\title{
Studying Relationship of Impact Value and Other Metal Material Performance
}

\author{
HAN Guohui ${ }^{1}$, SHI Tielin ${ }^{2}$ \\ School of Mechanical Science \& Engineering of HUST, \\ Huazhong University of Science and Technology , Wuhan, 430077, China \\ Email: rosa60@126.com
}

Keywords: impact value, stress concentrated coefficients, crack forming energy.

Abstract. the relationship between loopholes of stress concentrated coefficients and stress consolidate coefficients were illustrated; The relationship between impact value and loopholes sensitivity were found ; The relationship between crack forming energy and crack forming life was studied.

\section{Introduction}

The essence of the relationship between impact value and other mechanical properties is the sensitivity of sample with or without notch to the notch. Impact test is sensitive to structure defect of material. The test can sensitively reflect the macroscopic defects of material and tiny change of microstructure. Thus impact test can be used as one of the most effective methods to inspect the quality of smelting, heat treatment and the hot working process [1].

For some parts working under special conditions, such as shells and armor plate that bear high impact energy, the impact value is an important resistance index. For some machine parts bearing high energy impact, the impact value can be also used as a structure capacity index to prevent brittle fracture.

\section{The relation between stress concentration factor of notch and stress intensification factor}

Stress is the result of the loads, while strength is the performance of the material. When the loads increase to a certain value, material yields or fractures, and the stress value is called yield strength and fracture strength ${ }^{[2]}$ The stress value is called the yield stress or fracture stress.

Stress concentration factor is used to express that the nominal stress is concentrated on the notch root or front end of the crack:

$$
K t=\sigma_{m} / \sigma_{n}
$$

1)

In the expression: $\sigma_{\mathrm{m}}$ indicates the maximum stress of notch;

$\sigma_{\mathrm{n}}$ indicates nominal stress(Net cross section area divided by external load of the sample).

It should be indicated that $\sigma_{\mathrm{m}}$ does not exceed the material's elastic limit, so $\mathrm{Kt}$ is only associated with the geometric shape of notch. Therefore, it is called geometric elastic stress concentration factor.

However, stress strengthening factor $Q$ is related to strength. Since the plastic deformation is constrained by the deformation of the surrounding material, the yield stress of materials in plastic deformation increases, and the strengthening effect is enhanced. This kind of strengthening is characterized by stress strengthening factor $Q$. Based on slip-line field theory, the research results for v-notch are shown in Figure 1. 


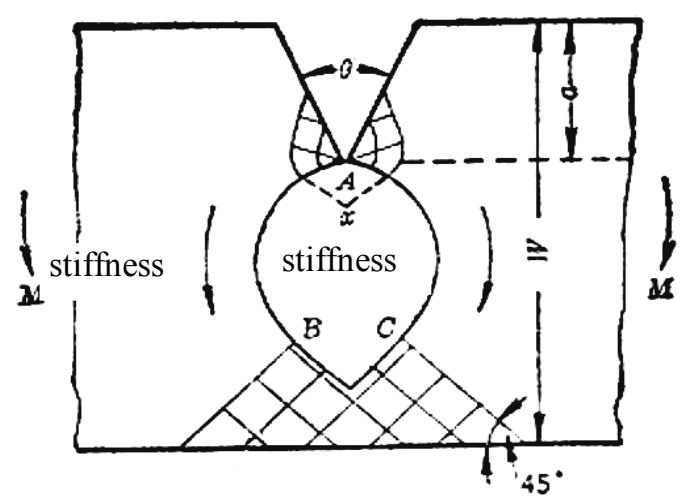

Figure 1 Slip line distribution for V-notch

Maximum value of $\sigma_{\mathrm{y}}$ is located at point $x$ in the figure. When $\theta$ is greater than 6.4 degrees, there is the following relation:

$$
\sigma_{y(\max )}=2 \tau_{s}\left(1+\frac{\pi}{2}-\frac{Q}{2}\right)
$$

Here the stress strengthening factor ${ }_{Q}$ is introduced with the following meaning:

$$
Q=\frac{\sigma_{y(\max )}}{2 \tau_{s}}=\frac{\sigma_{y(\max )}}{\sigma_{s}}
$$

3 )

The strengthening effect is due to the constraint from plastic deformation. Thus $Q$ is also called plastic constraint factor.

In the presence of notch or cracks, stress concentration and strengthening coexisting at the root or front end of the notch makes the material difficult to deform or yield. Therefore, the problem of whether the impact value can reflect the notch sensitivity is discussed.

\section{Comparison between impact energy and material notch sensitivity}

The existence of the notch will cause stress concentration and strain concentration at notch root. The notch will in three-way stress state, which constrains the plastic deformation of the material and improves the material yield strength ${ }^{[3]}$. This increase can be represented by stress strengthening factor $Q$. When $Q$ is large enough, brittle fracture occurs without yielding. Therefore, brittle fracture criterion of the material is:

$$
Q \sigma_{s} \geq \sigma_{y(\max )}=\sigma_{f}
$$

\section{4 )}

where $\sigma_{f}$ is brittle fracture strength.

Digital impact test is used to assess the material's notch sensitivity, aiming to increase the value of $Q$ and cause the material to be in brittle fracture state. Similarly, improving the loading speed can also improve the yield strength of the materials. Besides, under the action of impact load, the relaxation time of stress concentration may be greatly shortened. This will increase the value of $Q$ and make it easier for materials to reach brittle state. 
Table 1 is digital impact test results of 40CRMNSIMOA steel under different heat treatment conditions, $(\perp$ type notch is linear, radius of root being $0.06 \mathrm{~mm})$

Table 1 Digital impact test results of 40CrMnSiMoA

\begin{tabular}{|c|c|c|c|c|c|c|c|}
\hline $\begin{array}{l}\text { Heat treatment process } \\
\text { and code }\end{array}$ & $\begin{array}{l}\text { Notch } \\
\text { Type }\end{array}$ & $\begin{array}{c}F_{\mathrm{m}} \\
(\mathrm{kg})\end{array}$ & $\begin{array}{c}a_{\mathrm{k}} \\
\left(\mathrm{MJ} / \mathrm{m}^{2}\right)\end{array}$ & $A_{\mathrm{k}}(\mathrm{J})$ & $A_{i}(\mathrm{~J})$ & $A_{\mathrm{p}}(\mathrm{J})$ & $A_{i} / A_{\mathrm{K}}$ \\
\hline \multirow{2}{*}{$\begin{array}{l}\text { Isothermal tempering at } \\
190^{\circ} \mathrm{C} \text { for } 60 \text { minutes, and } \\
\text { tempering at } 260{ }^{\circ} \mathrm{C} \text { for } 4 \\
\text { hours(M 190T) }\end{array}$} & $\mathrm{U}$ & 394.6 & 0.440 & 33.9 & 26.6 & 7.3 & 0.78 \\
\hline & V & 308.6 & 0.223 & 18.2 & 12.3 & 5.8 & 0.68 \\
\hline \multirow{2}{*}{$\begin{array}{l}\text { Isothermal tempering at } \\
230{ }^{\circ} \mathrm{C} \text { for } 60 \text { minutes, and } \\
\text { tempering at } 260{ }^{\circ} \mathrm{C} \text { for } 4 \\
\text { hours(M 230T) }\end{array}$} & $\mathrm{U}$ & 401.8 & 0.479 & 37.1 & 29.7 & 7.4 & 0.80 \\
\hline & V & 315.6 & 0.241 & 18.9 & 12.7 & 6.2 & 0.67 \\
\hline \multirow{2}{*}{$\begin{array}{l}\text { Isothermal tempering at } \\
300^{\circ} \mathrm{C} \text { for } 30 \text { minutes, and } \\
\text { tempering at } 260{ }^{\circ} \mathrm{C} \text { for } 4 \\
\text { hours(B 30T) }\end{array}$} & $\mathrm{U}$ & 391.8 & 0.655 & 50.9 & 40.1 & 10.8 & 0.79 \\
\hline & V & 329.9 & 0.295 & 24.0 & 17.4 & 6.6 & 0.72 \\
\hline \multirow{2}{*}{$\begin{array}{l}\text { Isothermal tempering at } \\
300{ }^{\circ} \mathrm{C} \text { for } 60 \text { minutes, and } \\
\text { tempering at } 260{ }^{\circ} \mathrm{C} \text { for } 4 \\
\text { hours(B 60T) }\end{array}$} & $\mathrm{U}$ & 389.7 & 0.668 & 51.9 & 41.0 & 10.9 & 0.79 \\
\hline & V & 347.9 & 0.341 & 26.8 & 20.5 & 6.3 & 0.77 \\
\hline \multirow{2}{*}{$\begin{array}{l}\text { Isothermal tempering at } \\
300{ }^{\circ} \mathrm{C} \text { for } 60 \text { minutes, and } \\
\text { no tempering } \\
\text { ( B } 60 \text { ) }\end{array}$} & $\mathrm{U}$ & 388.6 & 0.662 & 51.9 & 37.9 & 14.6 & 0.73 \\
\hline & V & 336.6 & 0.311 & 23.6 & 17.1 & 6.8 & 0.72 \\
\hline
\end{tabular}

It can be seen from table 1 that the bainite structure (B30T, B60T, B60) of this steel has a higher AK value than that of martensite structure (M190T M230T). This is consistent with notch specimen impact test results of this steel, showing that bainite has lower notch sensitivity than martensite.

In digital impact test, the trend that notch specimen's tensile strength $\sigma_{\mathrm{bH}}$ increases with reduction of oblique angle $\theta$ is often used to compare the notch sensitivity[4]. In the u-shaped specimen, the trend that the maximum impact Fm increases with the reduction of notch radius $\rho$ is used to compare the material notch sensitivity. Figure 2 and figure 3 are $\sigma_{\mathrm{bH}}-\theta$ and $F_{\max }-\rho$ relation curves of bainite structure and martensite structure of 40CRMNSIMOA steel, respectively. 


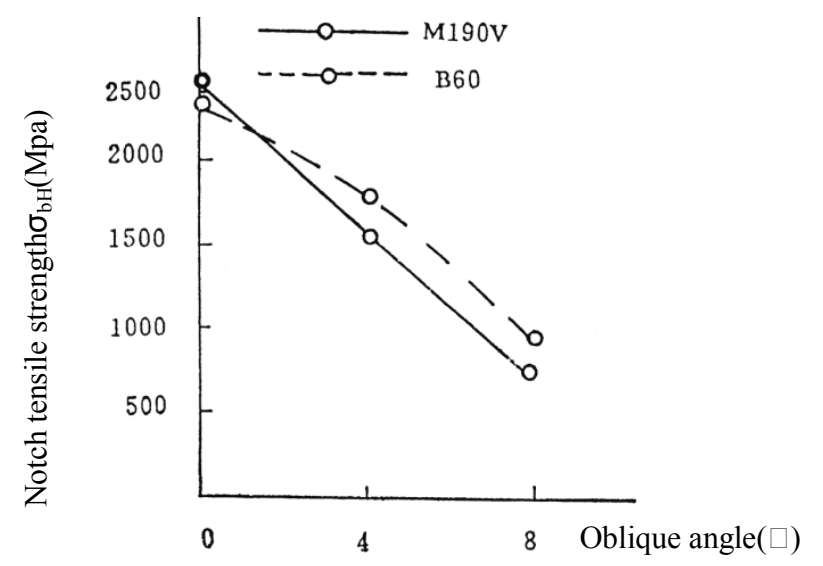

Figure $2 \sigma b H-\theta$ curve of $40 \mathrm{CrMnSiMoVA}$ steel notch specimen in askew tensile test

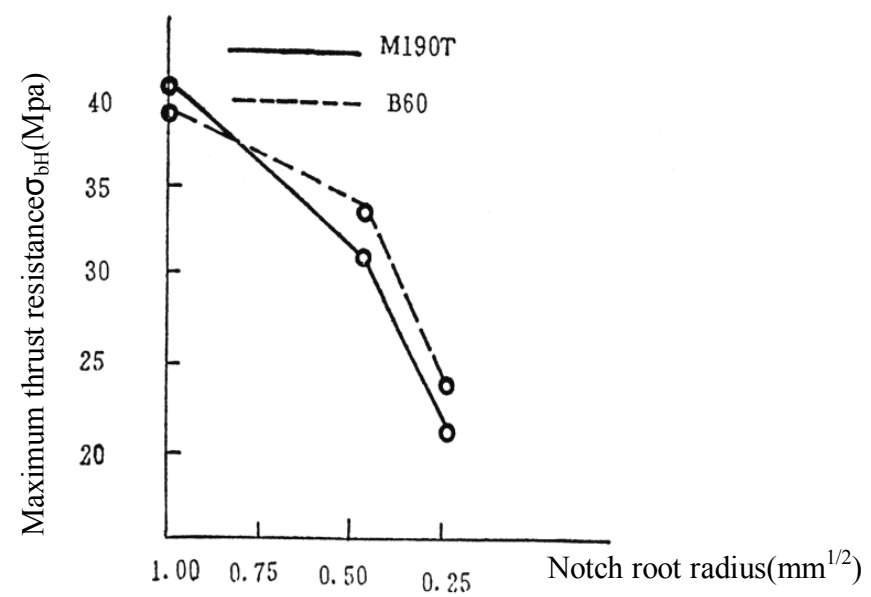

Figure 3: $F_{\max }-\sqrt{\rho}$ relation of $40 \mathrm{CrMnSiVA}$ steel notch specimen in impact test

From the two curves it is not hard to find that two types of method for expressing notch sensitivity have a fully consistent variation rule. When $\theta=0$, the $\sigma \mathrm{bH}$ of martensitic structure is higher than that of bainite structure. Also, for u-shaped notch specimen, the former's Fmax is slightly higher than the latter's. With increasing or decreasing of $\theta, \sigma b H$ or Fmax values of bainite structure are both higher than that of martensitic structure.

\section{Relation between the work of forming impact crack and the life of fatigue crack}

Metal fatigue life consists of two parts, namely, fatigue crack nucleation life and crack propagation life. In order to improve fatigue crack nucleation life, the effective method is surface strengthening treatment, such as shot peening, rolling, carburizing, nitriding, surface high-frequency quenching. Since the metal surface is likely to produce the core of fatigue crack easy and actual parts mostly bear alternating bending or alternating torsion load, surface stress is usually the largest. Surface strengthening processing, therefore, becomes the effective way to improve the fatigue limit.

The mechanism of surface treatment improving fatigue limit is as follows: surface strengthening increases the strength of surface, which in turn improves the fatigue limit of the surface. Moreover, the existence of strengthened layer makes the surface to produce compressive stress, thus reducing the tensile stress produced by the surface layer under cyclic loading. Hence the fatigue crack is not easy to produce or extend. See figure 4 . The beneficial effects are more significant to notch specimen or parts. The residual compressive stress is also concentrate at notch, which effectively reduces the concentration of tensile stress. 


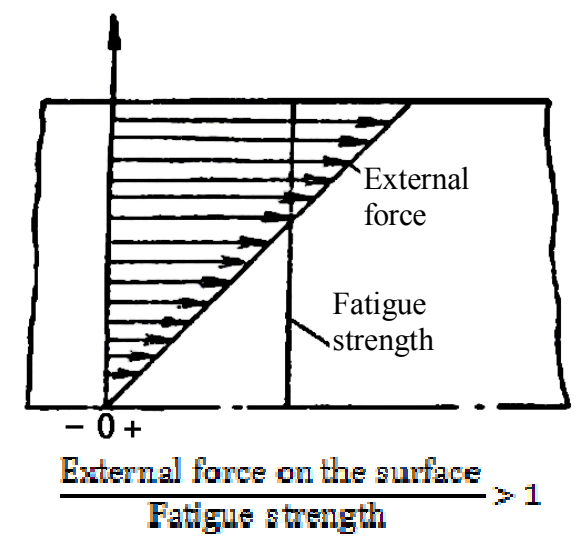

Figure 4 Existence of surface strengthening layer improves the fatigue limit

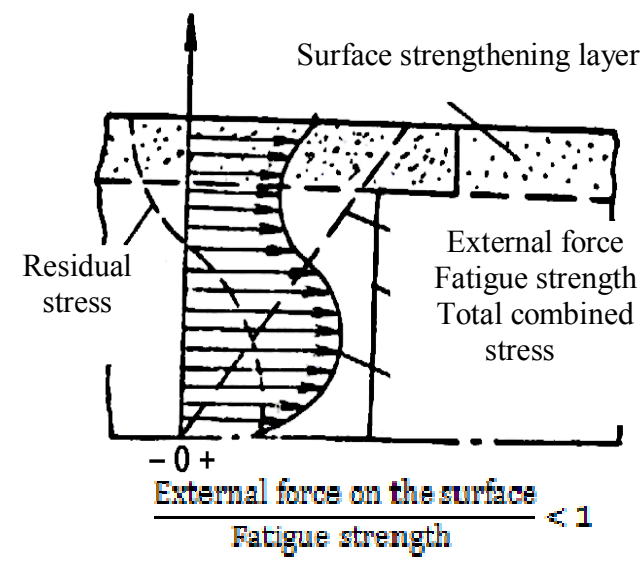

Figure 5 Existence of surface strengthening layer improves the fatigue limit

Stress state of specimen in three-point bending test is very similar to that in alternating load fatigue test as shown in Figure5. The notch of the specimen is subject to tensile stress, and the tensile stress is the largest on the surface of notch. The difference is that there is a change of tensile stress in impact test. So the result lays a theoretical basis to research the relation between fatigue limit and impact work, and the relation between crack formation work and propagation work. Through the instrumented impact test, the impact force-displacement curve is obtained as shown in figure 6: In force-displacement curve, area from $S=0$ to $S=S t$ is the value AK of impact work. Crack formation work is expressed as WI[5], which is area from $\mathrm{S}=0$ to $\mathrm{S}=\mathrm{Sm}$ in force-displacement curve.

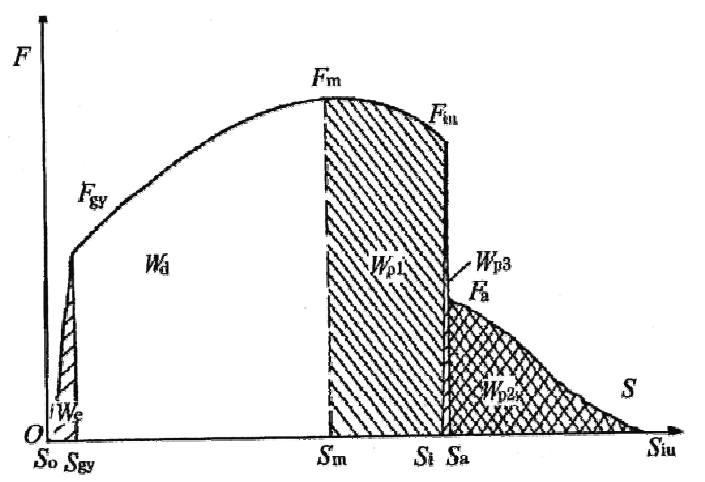

Figure 6 Force - displacement curve 
For high strength and super strength material, its high notch sensitivity has become an important issue that restricts the improvement of strength level. So the magnitude of the crack formation work of super strength material has a certain relationship with the difficulty of crack formation. It can be seen from pull-pull fatigue testing results of 40CrMoSiMoVA steel notch specimen (see table 2) that bainite structure with higher WI value has longer fatigue life than that of martensitic structure with lower WI value under the same stress. Because the ratio of fatigue crack formation life and total life is further improved, the bainite structure with high ${ }^{a_{\mathrm{k}}}$ value has more excellent fatigue performance. It is also suggested that $a_{\mathrm{k}}$ value has greater influence on fatigue crack formation life of notch specimen.

Table 2 Pull-pull fatigue testing results of 40CrMoSiMoVA steel notch specimen

\begin{tabular}{|c|c|c|c|c|}
\hline $\begin{array}{c}\text { Heat } \\
\text { treatment } \\
\text { process }\end{array}$ & \multirow{2}{*}{$\begin{array}{c}\text { WI } \\
(\mathrm{J} / \mathrm{cm} 2)\end{array}$} & \multicolumn{3}{|c|}{$\begin{array}{c}\text { Total fatigue life(Week) Force } \\
\text { unit(MPa) }\end{array}$} \\
\cline { 3 - 5 } M190T & 60 & 1472 & 2727 & 8094 \\
\hline B60T & 76 & - & 4066 & 21202 \\
\hline B60 & 72 & 1770 & 4287 & - \\
\hline
\end{tabular}

\section{Conclusions}

1) Stress strengthening factor is directly proportional to the maximum stress at notch.

2) Tensile strength of notch specimen $\sigma b H$ increases with reduction of oblique angle $\theta$. In the u-shape specimen, the maximum impact Fm increases with the reduction of notch radius $\rho$.

3) For high strength and super strength material, AK value has greater influence on the crack formation life of notch specimen;

4) the material with higher $\mathrm{AK}$ value has longer fatigue life than that of lower $\mathrm{AK}$ value under the same stress.

\section{References}

[1] Tang Zhenting The new development of impact test. Physical Test, 2003, (6) : 1-3.

[2] Compiled by Zhou Shunsu, Steel brittleness and brittle fracture of engineering structures, Shanghai Science and Technology Press, 1983, 8.

[3] Compiled by Tang Zhenting, Manual of Mechanical Engineering Material Test, Article 3 of Mechanics Volume, Liaoning Science and Technology Press, 2001, 12.

[4] M.V.Hosur, M.Abdullash, S.Jeelani, "Manufacturing and low-velocity impact characterigation of hollow integrated core sandwich composites with hybrid face sheets" Composites Structures 65(2004) 103-115 .

[5]Tang Zhenting, The measurement and application of impact energy eigenvalue, Physical Test, 2004, (6) : 21-23. 